Ocean Dynamics

April 2015, Volume 65, Issue 4, Pages 607-616

http://dx.doi.org/10.1007/s10236-015-0818-x

http://archimer.ifremer.fr/doc/00254/36539/

(c) Springer-Verlag Berlin Heidelberg 2015

\title{
Numerical modelling of mixed-sediment consolidation
}

\author{
Grasso Florent ${ }^{1,{ }^{*}}$, Le Hir Pierre ${ }^{1}$, Bassoullet Philippe ${ }^{1}$ \\ ${ }^{1}$ IFREMER-DYNECO/PHYSED, Centre de Bretagne, BP 70, 29280, Plouzané, France \\ *Corresponding author : Florent Grasso, email address : florent.grasso@ifremer.fr
}

\begin{abstract}
:
Sediment transport modelling in estuarine environments, characterised by cohesive and non-cohesive sediment mixtures, has to consider a time variation of erodibility due to consolidation. Generally, validated by settling column experiments, mud consolidation is now fairly well simulated; however, numerical models still have difficulty to simulate accurately the sedimentation and consolidation of mixed sediments for a wide range of initial conditions. This is partly due to the difficulty to formulate the contribution of sand in the hindered settling regime when segregation does not clearly occur. Based on extensive settling experiments with mud-sand mixtures, the objective of this study was to improve the numerical modelling of mixed-sediment consolidation by focusing on segregation processes. We used constitutive relationships following the fractal theory associated with a new segregation formulation based on the relative mud concentration. Using specific sets of parameters calibrated for each testwith different initial sediment concentration and sand content-the model achieved excellent prediction skills for simulating sediment height evolutions and concentration vertical profiles. It highlighted the model capacity to simulate properly the segregation occurrence for mud-sand mixtures characterised by a wide range of initial conditions. Nevertheless, calibration parameters varied significantly, as the fractal number ranged from 2.64 to 2.77 . This study investigated the relevance of using a common set of parameters, which is generally required for $3 D$ sediment transport modelling. Simulations were less accurate but remained satisfactory in an operational approach. Finally, a specific formulation for natural estuarine environments was proposed, simulating correctly the sedimentation-consolidation processes of mud-sand mixtures through 3D sediment transport modelling.
\end{abstract}

Keywords : Mud-sand mixtures, Hindered settling, Consolidation, Experiments, Numerical modelling, Segregation 


\section{Introduction}

The simulation of cohesive sediments requires that a time variation of erodibility due to consolidation be taken into account (e.g. Van Ledden et al. 2004; Sanford 2008; Le Hir et al. 2011). Different stages characterize the sediment behaviour from suspension to compaction, namely: flocculation, settling and sedimentation, and consolidation (e.g. Imai 1981). This final stage is driven by pore water release: firstly without solid skeleton formation, named as the permeability regime, and secondly with solid skeleton formation, named as the effective stress regime (e.g. Dankers and Winterwerp 2007). To a lesser extent, the creep effect that consists in solid skeleton compression may then take place for long-term sediment consolidation (e.g. Merckelbach and Kranenburg 2004a).

Several techniques for simulating consolidation have been proposed in the literature. The simplest methods consist in: (i) splitting the sediment into layers characterized by their density and/or shear strength, and (ii) translating the consolidation into a residence time concept (e.g. Teisson 1991) or into a regular mass transfer with the underlying layer that is more consolidated (e.g. Le Hir and Karlilow 1992). Another empirical technique is based upon an increase of sediment density (or shear strength) at each time step for each layer, according to a relaxation law towards an equilibrium vertical density profile (e.g. Sanford 2008). Another family of consolidation closure comes from the Kynch theory, considering sedimentation as a vertical mass advection. In this case, a constitutive relationship relates the sedimentation rate to the sediment concentration and composition (e.g. Le Hir et al. 2001). The most comprehensive approach, at least for primary consolidation, comes from soil mechanics, considering that the density increase results from a vertical exchange of pore water (Gibson et al. 1967). In this case, the forcing is the pressure gradient associated with the vertical increase of total weight after deduction of the so-called "effective stress" (a stress which is not applied to pore water) and the hydrostatic water pressure.

The Gibson's theory was initially proposed for pure mud and related the pore water release to the sediment void ratio. Numerous studies based on Gibson's theory simulated mud consolidation with fairly good skills (e.g. Winterwerp and Van Kesteren 2004; De Boer et al. 2007; Thiebot et al. 2011; Chauchat et al. 2013); however, they rarely applied to mixed sediments. Some models considering mud-sand mixtures were proposed (e.g. Toorman 1996; Toorman 1999; Merckelbach and Kranenburg 2004a; Le Hir et al. 2011; Van and Pham Van Bang 2013), but most of them had difficulty to simulate accurately sediment consolidation for moderate to 
large sand contents (typically larger than 10-20\%) and for a wide range of initial conditions. In other words, calibrating and simulating one settling column experiment is affordable; however, it has been proven more difficult to simulate a dataset characterized by different initial sediment concentrations, sand contents and grain sizes (Bartholomeeusen et al. 2002).

The presence of sand strongly influences the settling and consolidation processes of mud. It modifies the hindered settling of cohesive sediments and segregation between mud and sand can take place (e.g. Migniot 1977; Toorman and Berlamont 1993; Torfs et al. 1996). Recently, Grasso et al. (2014) analyzed a large dataset of settling column experiments, with varying initial concentrations and sand contents, to improve the understanding of mixed-sediment consolidation for large sand content (15-50\%). As previously observed (e.g. Torfs et al. 1996), the authors confirmed that for a given initial mass concentration the consolidation was faster for larger initial sand contents. It resulted in accelerating the convergence to large final mass concentrations. Sand segregation was not always observed in their experiments and, interestingly, a threshold of the initial relative mud concentration, defined as the mud concentration in the space not occupied by sand (Waeles et al. 2008), appeared as a potential indicator for preventing segregation.

Based on the consolidation model developed by Le Hir et al. (2011), which presented good skills for simulating mud consolidation and the capacity to simulate segregation, the objective of this study was to focus on the numerical modelling of mud-sand mixture sedimentation and consolidation processes in comparison with experimental data. This study paid particular attention to the model capacity for simulating accurately segregation occurrence. In addition, the relevance of using a common set of calibration parameters for a wide range of initial conditions was investigated.

The overarching goal of this work was to improve the simulation of mud-sand segregation processes in mixed-sediment consolidation modelling, in order to improve prediction accuracy of 3D estuarine sediment transport models.

\section{Experimental data}

\subsection{Experimental set-up}


This study focused on sedimentation and consolidation tests based on 12 settling column experiments carried out with natural sediment mixtures collected in the Mont Saint Michel Bay (MSMB) and the Seine Estuary (SE), North-West of France (Grasso et al. 2014). Experiments started from vertically homogeneous mixtures and were carried out during 20 and 200 days for SE and MSMB, respectively. The time evolution of sediment height $h$ was obtained through measurements of the sediment-water interface at high frequency, especially at the beginning during the settling phase. Vertical profiles of sediment mass concentration $C_{f}$ were measured at the end of the experiments. In MSMB, sediment samples came from two different areas, Cancale and Hirel, spaced by few kilometres and characterized by different sand contents $n_{s}\left(n_{s}=15 \%\right.$ and $30 \%$ at Cancale and Hirel, respectively). Nevertheless, sediment exchanges between those two areas were regularly observed (e.g. Cayocca et al. 2006) and similar sediment properties can be considered (sediment modes, organic matter content, etc.). In SE, natural mud and sand were mixed to obtain mud-sand mixtures with initial sand contents ranging from 20 to 50\%. Sediment properties may be different between SE and MSMB; therefore, different consolidation behaviours might be expected. For the settling experiments presented here, initial sediment concentrations $C$ ranged from 54 to $600 \mathrm{~kg} / \mathrm{m}^{3}$ (see Table 1). As an example, the time evolution of the relative sediment sample height $h / h_{0}$ ( $h_{0}$ is the initial sediment height) and the final vertical profile of mass concentration $C_{f}$ for the sediment mixture MSMB - C3 (see Table 1) are illustrated in Fig. 1 (circles). z represents the vertical coordinate increasing upward with $z=0$ at the settling column bottom. Fig. 1a highlights the different regimes of the consolidation processes (e.g. Dankers and Winterwerp 2007): (i) the settling regime from $t=0$ to 0.2 days; (ii) the permeability regime (without effective stresses) from $t=0.2$ to 9 days, characterized by a linear trend in log$\log$ scale; and (iii) the effective stress regime (with permeability) from $t=9$ to 200 days. The inflection point readily observed at $t=0.2$ day corresponds to the end of the hindered settling regime. Nonetheless, it is worth pointing out that during this phase some sediment had already settled at the bottom of the column and started to consolidate in the permeability regime.

\subsection{Segregation}

Grasso et al. (2014) observed that the relative mud concentration appeared as a potential segregation indicator. It reads:

$$
C_{\text {relmud }}=\frac{C_{\text {mud }}}{1-\phi_{\text {sand }}}
$$


with $C_{m u d}$ the mass concentration of mud (clay and silt) and $\phi_{\text {sand }}$ the volumetric concentration of sand (grain diameter $>63 \mu \mathrm{m})$. Note that the relative mud concentration is directly related to the relative volume fraction of fine particles, defined as (e.g. Marckelbach and Kranenburg 2004b):

$\phi=\frac{\phi_{\text {mud }}}{1-\phi_{\text {sand }}}=\frac{C_{\text {relmud }}}{\rho_{\text {s }}}$

(2)

with $\phi_{\text {mud }}$ the volumetric concentration of mud and $\rho_{s}=2650 \mathrm{~kg} / \mathrm{m}^{3}$ the grain density. synthesizes 22 settling experiments from the literature for which segregation occurrence was determined, based on sediment concentration and grain size vertical profiles (Bartholomeeusen et al. 2002; Merckelbach and Kranenburg 2004b; Te Slaa et al. 2013; Van and Pham Van Bang 2013; Grasso et al. 2014). Although sediment properties and initial conditions were drastically different, as mass concentrations ranged from 64 to $893 \mathrm{~kg} / \mathrm{m}^{3}$ and sand contents ranged from 2 to $80 \%$, it appeared that no segregation took place for initial relative mud concentrations $C_{\text {relmud }} \geq 207 \mathrm{~kg} / \mathrm{m}^{3}$. Consequently, $C_{\text {relmud seg }} \sim 200 \mathrm{~kg} / \mathrm{m}^{3}$ could be used as a threshold for determining segregation occurrence and was implemented in the consolidation numerical model presented in the following section.

\section{Numerical model}

\subsection{Equations}

The consolidation model used in this study follows the modelling strategy presented by Le Hir et al. (2011). It is based on Toorman’s (1996) unifying theory for sedimentation and consolidation of several classes of sediment. Following Merckelbach’s derivation of Gibson equation, and using as state variable the mass concentration of each sediment class $C_{i}$, the mass conservation equation during consolidation can be written as:

$$
\frac{\partial C_{i}}{\partial t}=\frac{\partial}{\partial z}\left[\frac{k}{\rho_{w}} C_{i} \Delta(\text { load })\right] \text { with } \quad \Delta(\text { load })=C \frac{\rho_{s}-\rho_{w}}{\rho_{s}}+\frac{1}{g} \frac{\partial \sigma^{\prime}}{\partial z}
$$

where $C$ is the sediment total mass concentration, assuming the same grain density $\rho_{s}$ for all sediment classes $i, k$ is the permeability (m/s), $\rho_{w}$ is the water density, $g$ the gravity and $\sigma$ ' the effective stress. In order to account for segregation due to polydispersity during sedimentation, sedimentation rates are different for mud and sand classes. The mud class is driven by the sedimentation rate in Eq. 3 and the sand settling is defined as the 
maximum between the sedimentation rate in Eq. 3 and the hindered settling velocity $W s_{\text {si hindered }}$ of the sand class si considered. This latter formulation lies on the founding principle that, when no effective stress appears, there is a relationship between the common settling velocity of all particles and the pore water velocity related to the permeability (e.g. Been 1980 in Toorman 1996). In other words, it enables to relate a settling velocity to an equivalent settling permeability as:

$W_{s}=\frac{k}{(1+e)} \frac{\rho_{s}-\rho_{w}}{\rho_{w}}$

Consequently, including this polydisperse formulation in Eq. 3, the following equation is solved:

$$
\frac{\partial C_{i}}{\partial t}=\frac{\partial}{\partial z}\left[C_{i} M A X\left(\frac{k}{\rho_{w}} \Delta(\text { load }), W s_{\text {si, hindered }}\right)\right]
$$

As observed in Section 2.2, a threshold on the relative mud concentration is relevant to determine segregation occurrence. Therefore, a segregation formulation based on $C_{\text {relmud }}$ is used to express the hindered settling of sand class si as:

$$
W s_{\text {si,hindered }}=W s_{s i}\left[1-\frac{C_{\text {relmud }}}{\alpha}\right]^{p}
$$

where $W s_{s i}$ is the non-hindered settling velocity estimated by Souslby's (1997) formulation and the power $p$ is defined as 4.65 according to Richardson and Zaki's (1954) observations. $\alpha$ is a numerical parameter to be calibrated in order that the sand settling becomes hindered by fine (muddy) particles when their relative concentration get close to the threshold value $C_{\text {relmudseg }}$ (see Section 3.2). Note that this formulation is not applicable for pure sands and may be incorrect for very large sand contents. This point is discussed in Section 5 .

The resolution of Eq. 5 requires the specification of two constitutive relationships for the permeability and the effective stress, respectively (e.g. Alexis et al. 1992; Toorman 1999). Two different formulations to compute the permeability constitutive relationship are used. The first is related to the void ratio $e$ (e.g. Bartholomeeusen et al. 2002; Le Hir et al. 2011), which reads:

$$
k_{e}=k_{1} e^{k_{2}}
$$

and the second is related to the relative volume fraction of fine particles $\phi$, based on the fractal theory presented by Merckelbach and Kranenburg (2004a), expressed as:

$k_{\phi}=K_{k} \phi^{-n}$

with $n=2 /\left(3-n_{f}\right)$ and $n_{f}$ is the fractal number that characterizes the distribution of solids in the sediment. Similarly, this fractal theory enables to compute the effective stress as: 
where $k_{1}, k_{2}, K_{k}, K_{\sigma}$ and $n$ are parameters to be calibrated. This model simulates primary consolidation processes, but does not take into account the creep effect as it acts on long time scales that are out of the scope of this study.

The permeability formulations using $k_{e}$ (Eq. 7) and $k_{\phi}$ (Eq. 8) were independently tested. The fractal approach $\left(k_{\phi}\right)$ worked better to accurately simulate $h / h_{0}$ time evolution in the permeability regime, as illustrated in Fig. 1a (to compare the blue and red solid lines). However, Eq. 8 was not aimed at characterizing the settling processes and so overestimated the permeability in the settling regime. It was expressed in Eq. 4 that a settling velocity can be related to an equivalent settling permeability and the void ratio. Therefore, the hindered settling was simulated using $k_{e}$ formulation, in consistency with Eq. 5 . Numerically, the permeability $k$ is computed as the minimum between $k_{e}$ and $k_{\phi}\left(k=\operatorname{MIN}\left[k_{\phi}, k_{e}\right)\right.$ to follow $k_{e}$ in the settling regime and $k_{\phi}$ in the permeability regime. In addition, taking into account segregation via Eq. 6 improved the simulation accuracy in the settling regime and led to sand deposition on the bottom of the settling column experiment, as illustrated by the increasing mass concentration at $z=0-2 \mathrm{~cm}$ in Fig. $1 \mathrm{~b}$ (thick cyan line). Finally, the effective stress regime was correctly simulated following Eq. 9, leading to an asymptotic behaviour around $h / h_{0}=0.2$ (Fig. 1a).

Although the permeability formulation based on $k_{\phi}$ and $k_{e}\left(k=\operatorname{MIN}\left[k_{\phi}, k_{e}\right]\right)$ is potentially more accurate, it does not easily apply to a wide range of initial conditions ( $C \sim 50-400 \mathrm{~kg} / \mathrm{m}^{3}$, see Section 4.2 ). Thus, in the numerical simulations presented in Section 4, we decided to compare two modelling strategies for computing the permeability constitutive equation, namely: (i) Method 1 , with $k=\operatorname{MIN}\left[k_{\phi}, k_{e}\right]$; and (ii) Method 2, with $k=k_{e}$. In both Method 1 and 2, the segregation and effective stress were computed following Eqs. 6 and 9, respectively.

\subsection{Numerical model parameterization}

The constitutive relationships defined in the previous Section require empirical parameters to be calibrated $\left(k_{1}\right.$, $k_{2}, K_{k}, K_{\sigma}$ and $n$ ). Merckelbach and Kranenburg's (2004b) method was used to estimate $K_{k}, K_{\sigma}$ and $n$ by means of settling column experiment data $\left(h, C_{f}\right)$. Practically, $K_{k}$ and $n$ were estimated from sediment height time evolution in the permeability regime and $K_{\sigma}$ was estimated from the final vertical profile of sediment concentration. Nevertheless, this method has some limitations as it requires $\log (h)=\mathrm{f}(\log (t))$ to be linear in the permeability regime. For example, such a trend was not observed for settling experiments characterized by large initial sediment mass concentrations $\left(C_{0} \sim 400 \mathrm{~kg} / \mathrm{m}^{3}\right)$, as effective stresses appeared at the beginning and no 
pure permeability regime took place. $k_{1}$ and $k_{2}$ were evaluated by trial and error in order to simulate the rate of the sediment height decay.

It was also necessary to define $\alpha$ in Eq. 6 to simulate a segregation threshold around $C_{\text {relmud seg }} \sim 200 \mathrm{~kg} / \mathrm{m}^{3}$, as deduced from settling column experiments (see Section 2.2). Following Eq. 4, the hindered settling equivalent permeability can be written as:

$$
k_{W s . h i n d}=W s_{\text {hindered }}(1+e) \frac{\rho_{w}}{\rho_{s}-\rho_{w}}
$$

According to the proposed model (Eq. 5), the actual settling velocity is the maximum between the one deduced from the permeability $\left(k_{e}\right.$ or $k_{\phi}$ ) and the hindered settling velocity. Fig. 2 represents both laws, expressed as equivalent permeability, illustrating the intersection points that represent the segregation occurrence thresholds. In Eq. 6, the critical value $\alpha$ has been selected $\left(\alpha=250 \mathrm{~kg} / \mathrm{m}^{3}\right)$ in order that the $k_{W s}$ ind curve intersects $k_{e}$ and $k_{\phi}$ curves around $C_{\text {relmud }}=200-210 \mathrm{~kg} / \mathrm{m}^{3}$, in agreement with the experimental segregation threshold $\left(C_{\text {relmud seg }} \sim 200 \mathrm{~kg} / \mathrm{m}^{3}\right)$.

The numerical simulations were run in a $1 \mathrm{DV}$ model with initial layer thickness of $5 \mathrm{~mm}$. The layers had a constant thickness, except the one at the surface that could reduce to a minimum value of $0.01 \mathrm{~mm}$ before disappearing. Two classes of sediment (mud and sand) were defined from experimental grain size distributions. The mud and sand representative diameters were $d_{\text {mud }}=7 \mu \mathrm{m}$ and $d_{\text {sand }}=100 \mu \mathrm{m}$ in MSMB and $d_{\text {mud }}=20 \mu \mathrm{m}$ and $d_{\text {sand }}=210 \mu \mathrm{m}$ in SE.

\section{Validation and application of the sediment model}

\subsection{Numerical modelling of sedimentation-consolidation processes}

Following the Method $1\left(k=\operatorname{MIN}\left[k_{\phi}, k_{e}\right]\right)$ presented in Section 3.1, MSMB - Cancale experiments and simulations were compared for $h / h_{0}$ time evolution and $C_{f}$ vertical profiles (Fig. 3). These experiments were characterized by sediment mixtures with $15 \%$ of sand and initial mass concentrations $C=54,106$ and $201 \mathrm{~kg} / \mathrm{m}^{3}$

(see Table 1). Empirical parameters were calibrated individually according to Merckelbach and Kranenburg’s (2004b) method. The MSMB - C1 experiment $\left(C=405 \mathrm{~kg} / \mathrm{m}^{3}\right)$ is not presented as the empirical parameters could not be determined following Merckelbach and Kranenburg’s (2004b) method (see Section 3.2). Empirical 
parameters and prediction skill values are detailed in Table 3 for each simulation. The time evolution of the water-sediment interface was very accurately simulated for the three experiments (Fig. 3a), as confirmed by the excellent prediction skills $\left(r^{2}>0.99\right.$ and $e_{r m s} \leq 0.06$, with $r^{2}$ the squared correlation coefficient and $e_{r m s}$ the normalized root mean square error). The final vertical profiles of mass concentration were also successfully reproduced (Fig. 3b). Nonetheless, $C_{f}$ in MSMB - C2 was slightly overestimated along the profile, mainly due to the small error in simulating the final sediment height.

The time evolution of simulated concentration vertical profiles for MSMB - C3 experiment is presented in Fig. 4. It started from a vertically homogeneous concentration $\left(C_{0}=106 \mathrm{~kg} / \mathrm{m}^{3}\right)$ and finished at $t=100$ days with a double step-like profile (at $z=2$ and $18 \mathrm{~cm}$ ), typical pattern of segregation occurrence. From $t=0$ to 0.2 day, we observed two interfaces (for instance at $t=0.1$ day: $z_{1}=68 \mathrm{~cm}$ and $z_{2}=22 \mathrm{~cm}$ ): the upper one $\left(z_{1}\right.$ ) delimited the water and the sediment falling in the settling regime; and the lower one $\left(z_{2}\right)$ delimited the sediment falling in the settling regime and the sediment consolidating in the permeability regime, characterized by a slower sedimentation (e.g. Dankers and Winterwerp 2007). The converging interfaces merged at the end of the settling regime, here between $t=0.2$ and 0.3 day. This is entirely consistent with $h / h_{0}$ time evolution (red triangles in Fig. 3a), pointing out the settling/permeability regime boundary around $t=0.25$ day.

It turns out that Merckelbach and Kranenburg's (2004b) method was relevant to calibrate the constitutive relationship parameters in the permeability and effective stress regimes. However, for a given sediment, these parameters varied with the initial concentration. Recent studies mentioned that the calibrated fractal number varied with the initial sediment concentration (e.g. Van and Pham Van Bang 2013) and Te Slaa et al. (2013) used the initial solid volume fraction to calibrate their sedimentation simulations. We computed the fractal number $n_{f}$ from several settling experiment data collected in the literature and we explored it as a function of the initial relative mud concentration $C_{\text {relmud }}$ and sand content $n_{s}$ (Fig. 5). Interestingly, $n$ increased rather linearly with $C_{\text {relmud }}$, but it did not depend on the initial sand content. However, there are interests and motivations in converging toward a unique parameterization for a given sediment. For instance, in 3D estuarine sediment transport modelling, water column and sediment bed are usually dealt as two compartments and the initial sediment concentration of the deposit is arbitrary defined as a constant value. Therefore, it would appear difficult to consider dependence of parameters on this arbitrary initial sediment concentration. Consequently, the next section addresses the relevance of using a common parameterization for a wide range of initial conditions.

\subsection{Toward a common parameterization}


Although the Method $1\left(k=\operatorname{MIN}\left[k_{\phi}, k_{e}\right]\right)$ was very relevant with individual parameters, it led to poor prediction skills with a common set of parameters applied to a wide range of initial sediment concentrations $(\mathrm{C} \sim 50$ $\left.400 \mathrm{~kg} / \mathrm{m}^{3}\right)$. Thus, Method $2\left(k=k_{e}\right)$ was used in the present Section with the set of parameters given in Table 3 and applied to MSMB - Cancale (Fig. 6) and Hirel (Fig. 7) experiments.

For MSMB - Cancale experiments, the simulations of $h / h_{0}$ were less accurate than the ones presented in Section 4.1 (Fig. 6a); however, they were satisfactory in an operational approach ( $r^{2}=0.91$ to 0.98 and $e_{r m s}=0.06$ to 0.3$)$. The effective stress regime was correctly simulated, but the model had difficulty to simulate properly the settling and permeability regimes. Interestingly, the final vertical profiles of mass concentration were very well reproduced (Fig. 6b). The same set of parameters applied to MSMB - Hirel experiments led to slightly better prediction skills for $h / h_{0}$ simulations $\left(r^{2}=0.93\right.$ to 0.99 and $e_{r m s}=0.04$ to 0.26 , Fig. 7 a). As for Cancale, the final concentration profiles were accurately simulated (Fig. 7b). Especially, both segregation absence (MSMB - H1) and presence (MSMB - H2 to H4) were correctly reproduced. It confirms the model capacity to simulate properly segregation occurrence for mud-sand mixture sedimentation.

The influence of initial sand content on concentration vertical profiles has been investigated by means of numerical modelling for MSMB - Cancale $\left(n_{s}=15 \%\right)$ and Hirel $\left(n_{s}=30 \%\right)$ experiments (Fig. 8). For both absence (Fig. 8a) and presence (Fig. 8b and c) of segregation, the consolidation was faster for larger initial sand contents, leading to larger mass concentrations at $t=100$ days, as observed in settling experiments (e.g. Torfs et al. 1996; Grasso et al. 2014). Obviously, segregation was enhanced for larger $n_{s}$ (Fig. 8b); however, for low initial concentrations ( $C \sim 60 \mathrm{~kg} / \mathrm{m}^{3}$, Fig. 8c) when sedimentation was very fast, concentration profiles did not differ significantly between $n_{s}=15$ and $30 \%$. This is understandable as segregation could fully take place since the beginning of the simulation.

Once the common parameterization had been challenged for a sediment with varying initial concentrations and sand contents (MSMB - Cancale and Hirel), its relevance was questioned for another field area characterized by different sediment properties (sediment modes, organic matter content, etc.). Hence, the same set of parameters was applied to the Seine Estuary (SE) experiments for $n_{s}=20$ to $50 \%$ (Fig. 9). The model had difficulty to simulate accurately $h / h_{0}$ time evolution for SE -1 and $2\left(r^{2}=0.81\right.$ to 0.96 and $e_{r m s}=0.14$ to 0.24, Fig. 9a), but was clearly better for $\mathrm{SE}-3$ and $5\left(r^{2}=0.96\right.$ to 0.98 and $e_{r m s}=0.02$ to 0.06$)$. The $C_{f}$ vertical profiles were reasonably well reproduced (Fig. 9b); most of the discrepancies came from the error in simulating 
the final sediment height. Nonetheless, it points out that consolidation model parameters were to some extent dependent on the properties of the sediment used for the calibration.

The overarching objective of this study was to improve the numerical modelling of estuarine sediment transport. In such natural environments, the mass concentration of mud-sand mixture deposits hardly exceeds $100-150 \mathrm{~kg} / \mathrm{m}^{3}$ and a common parameterization can be proposed for this range of concentrations. Method 1 $\left(k=\operatorname{MIN}\left[k_{\phi}, k_{e}\right]\right)$ was applied to MSMB - C3-C4 and H3-H4 experiments $\left(C<120 \mathrm{~kg} / \mathrm{m}^{3}\right)$ with a common set of parameters given in Table 3. As presented in Fig. 10, the simulated $h / h_{0}$ matched correctly the measurements and good prediction skills were obtained $\left(r^{2} \geq 0.98\right.$ and $e_{r m s}=0.1$ to 0.14$)$. It represents a significant improvement compared to simulations based on the Method 2, as it almost reduced the $e_{r m s}$ by a factor of two. It highlights that such a common parameterization can provide good prediction skills to simulate sedimentation-consolidation processes of mud-sand mixtures through 3D sediment transport modelling.

\section{Discussion}

The numerical modelling of mud-sand mixture sedimentation and consolidation has been confronted to data from settling column experiments. Simulations based on individual parameterizations showed excellent prediction skills $\left(r^{2}>0.99\right.$ and $\left.e_{r m s} \leq 0.06\right)$. The settling regime was simulated combining: (i) a permeability formulation based on the void ratio and (ii) a hindered settling formulation that permits sand to settle faster than mud, and therefore, that permits to simulate segregation. The permeability and effective stress regimes were well described by Merckelbach and Kranenburg's (2004a) formulation based on the fractal theory (using the mud relative volume fraction), although the constitutive relationship parameters were dependent on the initial sediment concentration. Usually embedded in a 3D sediment transport model divided in two compartments - bed sediment and water column - (e.g. Le Hir et al. 2011), the model presented in this study simulates sedimentation and consolidation processes in the bed compartment only. For that reason, flocculation processes are not taken into account in this model, but they can be simulated in the water column compartment of the 3D model.

The analysis of sediment concentration vertical profiles highlighted the model capacity to simulate properly segregation occurrence (absence and presence) for mud-sand mixtures characterized by a wide range of initial concentrations and sand contents. Thus, the segregation formulation (Eq. 6) based on the relative mud concentration, associated with the segregation threshold $\left(C_{\text {relmud seg }} \sim 200 \mathrm{~kg} / \mathrm{m}^{3}\right)$ deduced from literature settling 
experiments, seems appropriate to simulate sand segregation. Nevertheless, Eq. 6 does not consider the influence of sediment grain sizes (or organic matter contents) on segregation processes. There might be a possibility to propose a formulation for $\alpha$ depending on the sediment grain size, instead of being constant as defined in this study. Furthermore, the segregation formulation proposed in Eq. 6 is not applicable for pure sands. Simulations were reasonably correct for large sand content $\left(n_{s}=50 \%\right)$ in the Seine Estuary experiments (SE $-1,3$ and 5), but more discrepancies have to be expected for larger sand contents $\left(n_{s}>50 \%\right)$. For such conditions, it would be necessary to take into account the effect of sand grains on hindered settling. In addition, using the segregation formulation with the appropriate segregation threshold ( $\left.C_{\text {relmud seg }}\right)$ enabled to predict correctly the time and space evolution of the settling and permeability sediment interfaces. It would be interesting to investigate the relation that may exist between this segregation threshold $C_{\text {relmud seg }}$ and the gelling point concentration $C_{g e l}$, but this is beyond the scope of this paper.

The coupling between a 1DV consolidation model and a 3D estuarine sediment transport model (e.g. Le Hir et al. 2011) generally requires a common set of parameters for the constitutive relationship calibration, as the deposit sediment concentration is usually defined as a constant. The permeability formulation based on the fractal theory was not appropriate to simulate a wide range of initial conditions $\left(\mathrm{C} \sim 50-400 \mathrm{~kg} / \mathrm{m}^{3}\right)$ with a common parameterization. Consequently, we showed that the sediment model using the permeability formulation based on the void ratio was, in an operational approach, satisfactory $\left(r^{2} \geq 0.91\right.$ and $\left.e_{r m s} \leq 0.3\right)$. Such a parameterization, however, did not necessarily apply to another field area with different sediment properties (e.g. sediment grain size, organic matter content). It emphasizes that sediment settling experiments are very helpful to calibrate the constitutive equation parameters to a specific area characterized by a typical sediment. In natural estuarine environments, most of sediment deposits do not exceed concentrations larger than approximately $100 \mathrm{~kg} / \mathrm{m}^{3}$. This value can thus be defined as the sediment concentration of "fresh deposit” in a 3D sediment transport model. For this range of concentrations $\left(C_{0}<120 \mathrm{~kg} / \mathrm{m}^{3}\right)$, this study proposed an upgraded common parameterization, with permeability computed as a function of the mud relative volume fraction and the void ratio, that achieved good prediction skills $\left(r^{2} \geq 0.98\right.$ and $\left.e_{r m s} \leq 0.14\right)$.

In conclusion, the numerical model presented in this study has been shown to correctly simulate sedimentation and consolidation processes for mixed sediments with moderate to large sand content (15 to $50 \%)$. The influence of segregation processes on consolidation dynamics was deeply investigated and a new formulation for simulating segregation occurrence was proposed. Finally, this work presented a common set of 
parameters that can produce a reasonable level of predictive accuracy for mixed-sediment consolidation embedded within a 3D estuarine sediment transport model.

\section{Acknowledgements}

The authors want to thank the scientific research programs Seine-Aval III and IV for funding the research projects that enabled carrying out the experiments presented in this study.

\section{References}

Alexis A, Bassoullet P, Le Hir P, Teisson C (1992) Proceedings of the 23rd International Conference on Coastal Engineering: ICCE 1992 pp.2950-2961

Bartholomeeusen G, Sills GC, Znidarcic D, Van Kesteren W, Merckelbach LM, Pyke R, Carrier WD, Lin H, Penumadu D, Winterwerp H, Masala S, Chan D (2002) Sidere: numerical prediction of large-strain consolidation. Géotechnique 52(9):639-48.

Cayocca F, Dussauze M, Le Hir P, Bassoullet P, Jestin H (2006) Modélisation hydro-sédimentaire de la baie du Mont Saint-Michel. IX èmes Journées Nationales Génie Côtier-Génie Civil, Brest, 12-14 septembre 2006.

Chauchat J, Guillou S, Pham Van Bang D, Nguyen KD (2013) Modelling sedimentation-consolidation in the framework of a one-dimensional $\backslash$ two-phase flow model. J Hydrau Res 51(3):293-305.

Dankers PJT, Winterwerp JC (2007) Hindered settling of mud flocs: theory and validation. Cont Shelf Res 27(14):1893-1907.

De Boer GJ, Merckelbach LM, Winterwerp JC (2007) A parameterised consolidation model for cohesive sediments. In Estuarine and Coastal Fine Sediment Dynamics, Maa, JP-Y, Sanford LP, and Schoellhamer DH (Eds), Proceedings in Marine Science 8:243-262.

Gibson RE, England GL, Hussey MJL (1967) The theory of one dimensional consolidation of saturated clays. Géotechnique 17:261-273.

Grasso F, Le Hir P, Bassoullet P (2014) Analysis of mixed-sediment consolidation experiments. Proceedings of the 13th Journées Nationales Génie Côtier - Génie Civil, Dunkerque, France.

Imai G (1981) Experimental Studies on Sedimentation Mechanism and Sediment Formation of Clay Materials. Soils and Foundations, Japanese Society of Soil Mechanics and Foundation Engineering 21(1):7-20. 
Le Hir P, Karlilow N (1992) Sediment transport modelling in a macrotidal estuary: do we need to account for consolidation processes? Proceedings of the 23rd International Conference on Coastal Engineering: ICCE 1992 pp.3121-3134.

Le Hir P, Ficht A, Silva Jacinto R, Lesueur P, Dupont J-P, Lafite R, Brenon I, Thouvenin B, Cugier P (2001) Fine sediment transport and accumulations at the mouth of the Seine estuary (France). Estuaries 24(6B):950-963.

Le Hir P, Cayocca F, Waeles B (2011) Dynamics of sand and mud mixtures: a multiprocess-based modelling strategy. Cont Shelf Res 31:S135-S149.

Merckelbach L, Kranenburg C (2004a) Equations for effective stress and permeability of soft mud-sand mixtures. Géotechnique 54(4):235-243.

Merckelbach L, Kranenburg C (2004b) Determining effective stress and permeability equations for soft mud from simple laboratory experiments. Géotechnique 54(9) :581-591.

Migniot C (1989) Tassement et rhéologie des vases, 1ère partie. La Houille Blanche 1:11-29.

Richardson JF, Zaki WN (1954) The sedimentation of a suspension of uniform spheres under conditions of viscous flow. Chem Eng Sci 3:65-73.

Sanford L (2008) Modeling a dynamically varying mixed sediment bed with erosion, deposition, bioturbation, consolidation and armouring. Comp Geosci 34:1263-1283.

Soulsby R (1997) Dynamics of Marine Sands: A Manual for Practical Applications. Thomas Telford.

Teisson C (1991) Cohesive suspended sediment transport: feasibility and limitations of numerical modelling. J of Hydrau Res 29(6):755-769.

Thiebot J, Guillou S, Brun-Cottan JC (2011) An optimisation method for determining permeability and effective stress relationships of consolidating cohesive sediment deposits. Cont Shelf Res 31:S117-S123.

Toorman EA (1996) Sedimentation and self-weight consolidation: general unifying theory. Géoetchnique 46(1):103-113.

Toorman EA (1999) Sedimentation and self-weight consolidation: constitutive equations and numerical modelling. Géotechnique 49(6):709-26.

Toorman EA, Berlamont JE (1993) Settling and consolidation of mixtures of cohesive and non-cohesive sediments. Adv Hydro-Sci Eng 1:606-613.

Torfs H, Mitchener H, Huysentruyt H, Toorman E (1996) Settling and consolidation of mud/sand mixtures. Coast Eng 29:27-45. 
Van LA, Pham Van Bang D (2013) Hindered settling of sand/mud flocs mixtures: From model formulation to numerical validation. Adv Wat Resour 53:1-11.

Van Ledden M, van Kesteren WGM, Winterwerp JC (2004) A conceptual framework for the erosion of sandmud mixtures. Cont Shelf Res 24:1-11.

Waeles B, Le Hir P, Lesueur P (2008). A 3D morphodynamic process-based modelling of a mixed sand/mud coastal environment: the Seine estuary, France. In Sediment and Ecohydraulics: INTERCOH 2005 (Elsevier).

Winterwerp JC, van Kesteren WGM (2004) Introduction to the Physics of Cohesive Sediment in the Marine Environment. Elsevier, New York. 

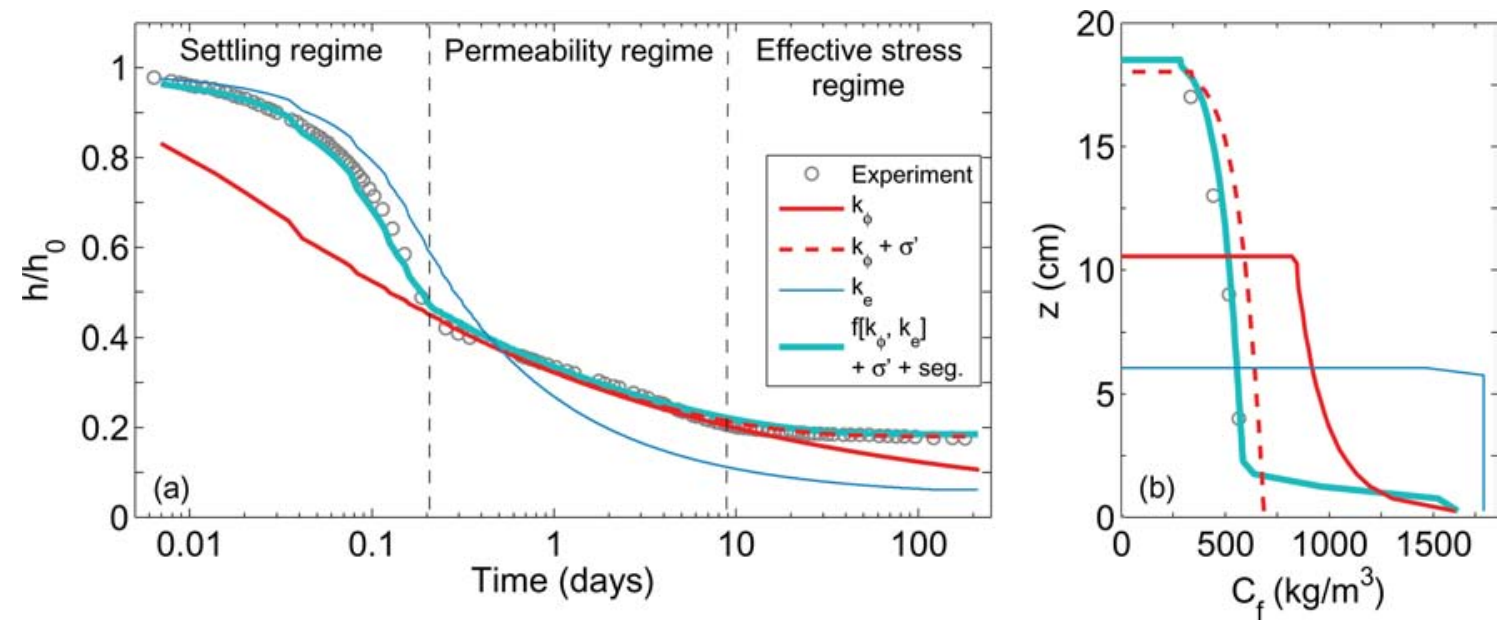

Fig. 1 (a) Time evolution of the relative sediment height $h / h_{0}$ and (b) final vertical profiles of sediment mass concentration $C_{f}$ for MSMB - C3 experiment (circles) and numerical simulations considering: $k_{\phi}$ from Eq. 8 (solid red line); $k_{\phi}$ and $\sigma^{\prime}$ from Eqs. 8 and 9 (dashed red line); $k_{e}$ from Eq. 7 (thin blue line); $k=\operatorname{MIN}\left[k_{\phi}, k_{e}\right], \sigma^{\prime}$ and segregation from Eqs. 6 to 9 (thick cyan line).

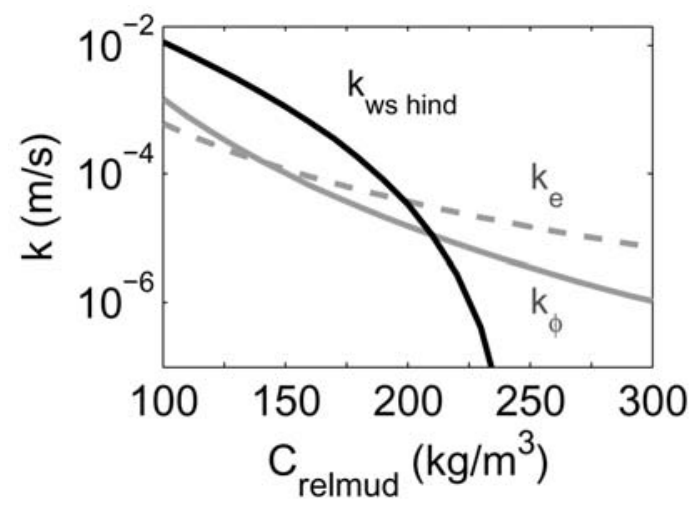

Fig. 2 Permeability via void ratio $k_{e}$ (dashed grey line), permeability via mud relative volume fraction $k_{\phi}$ (solid grey line) and hindered settling equivalent permeability $k_{\text {ws hind }}$ (solid black line) computed from Eqs. 7, 8 and 10 , respectively, as functions of the relative mud concentration $C_{\text {relmud. }}$ The intersection points between grey and black lines represent the segregation threshold $C_{\text {relmud seg. }}$ 

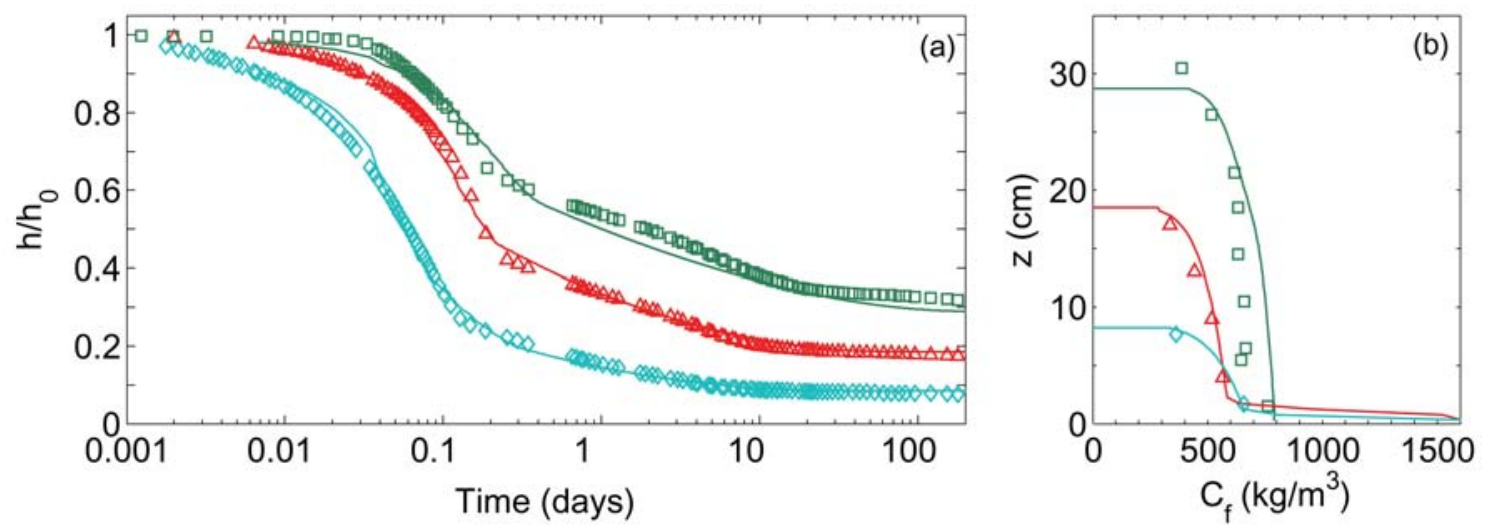

Fig. 3 (a) Time evolution of the relative sediment height $h / h_{0}$ and (b) final vertical profiles of sediment mass concentration $C_{f}$ for MSMB - Cancale experiments (symbols) and numerical simulations (lines) following the Method $1\left(k=\operatorname{MIN}\left[k_{\phi}, k_{e}\right]\right)$ with individual set of parameters (see Table 3): MSMB - C2 (squares, green); MSMB - C3 (triangles, red); MSMB - C4 (diamonds, cyan).

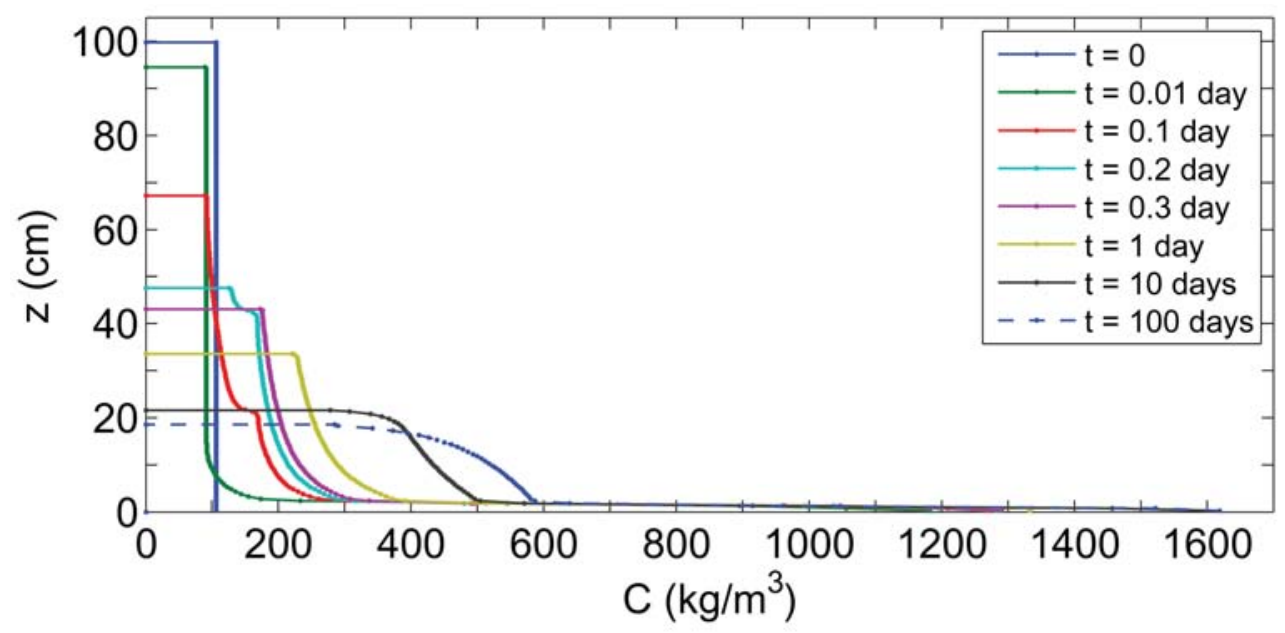

Fig. 4 Time evolution of mass concentration vertical profiles $C$ for MSMB - C3 experiment simulated following the Method $1\left(k=\operatorname{MIN}\left[k_{\phi}, k_{e}\right]\right)$ with individual set of parameters (see Table 3). 


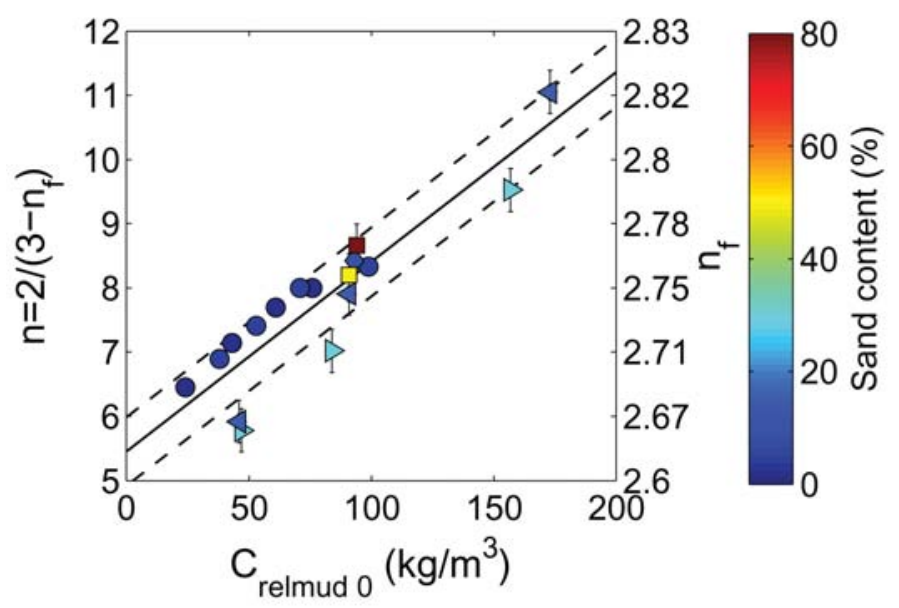

Fig. 5 Relation between the constitutive relationship parameter $n$ (related to the fractal number $n_{f}$ ), the initial relative mud concentration $C_{\text {relmud }}$ and the initial sand content for several data from the literature: Merckelbach and Kranenburg (2004b) (diamond); Te Slaa et al. (2013) (circles); MSMB - Cancale (Grasso et al. 2014) (leftward triangles); MSMB - Hirel (Grasso et al. 2014) (rightward triangles); SE - Mel (Grasso et al. 2014) (squares). The solid line is the least square fit linear interpolation and the dashed lines represent \pm one standard deviation.
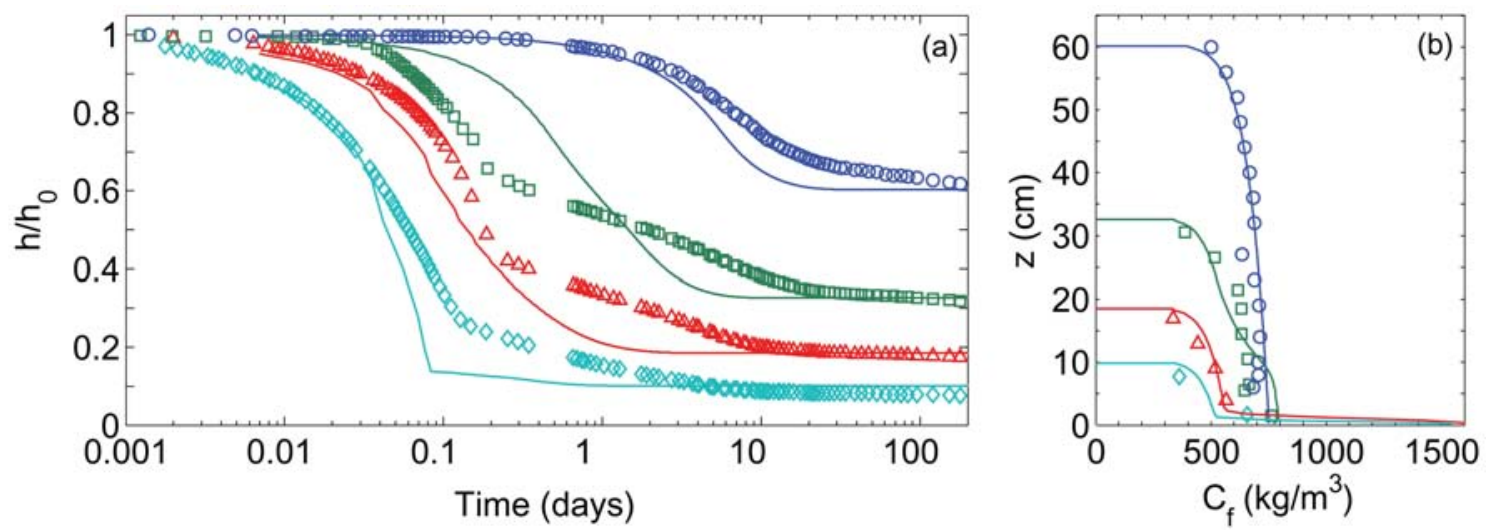

Fig. 6 (a) Time evolution of the relative sediment height $h / h_{0}$ and (b) final vertical profiles of sediment mass concentration $C_{f}$ for MSMB - Cancale experiments (symbols) and numerical simulations (lines) following the Method $2\left(k=k_{e}\right)$ with a common set of parameters (see Table 3): MSMB - C1 (circles, blue); MSMB - C2 (squares, green); MSMB - C3 (triangles, red); MSMB - C4 (diamonds, cyan). 

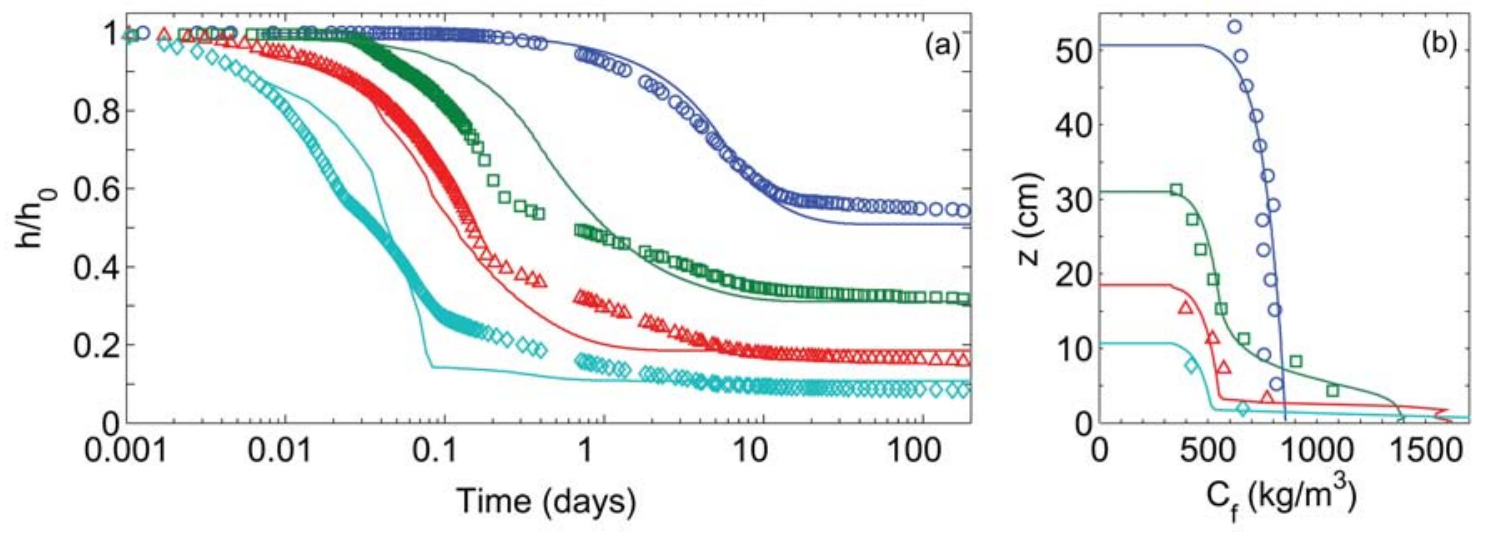

Fig. 7 (a) Time evolution of the relative sediment height $h / h_{0}$ and (b) final vertical profiles of sediment mass concentration $C_{f}$ for MSMB - Hirel experiments (symbols) and numerical simulations (lines) following the Method $2\left(k=k_{e}\right)$ with a common set of parameters (see Table 3): MSMB - H1 (circles, blue); MSMB - H2 (squares, green); MSMB - H3 (triangles, red); MSMB - H4 (diamonds, cyan).
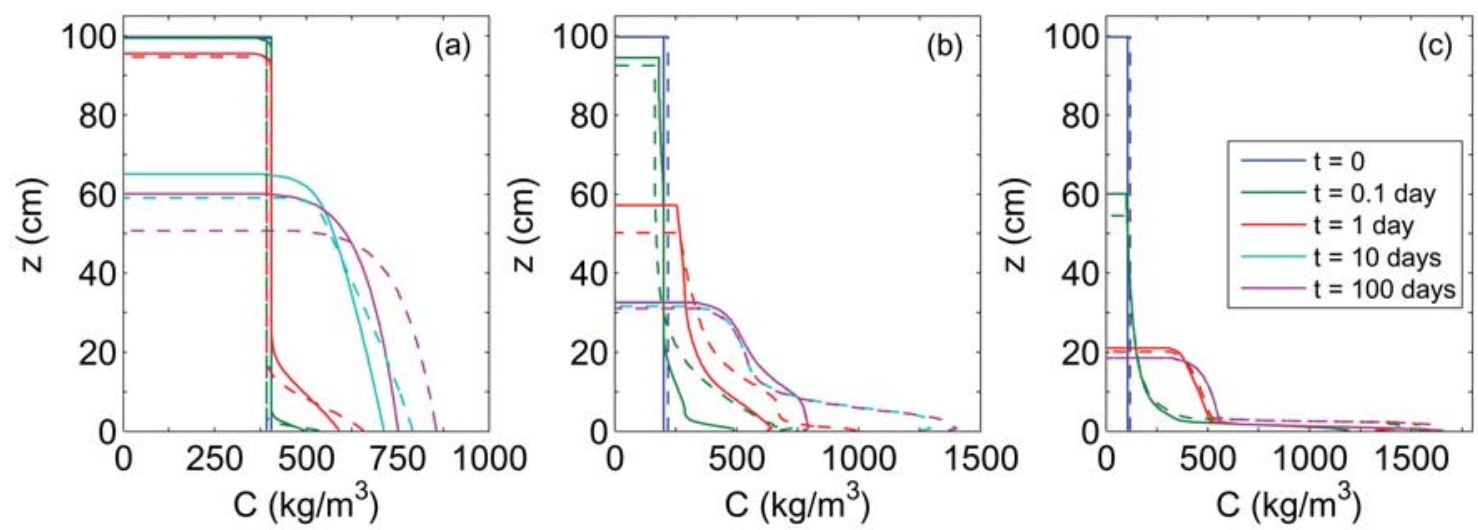

Fig. 8 Time evolution of mass concentration vertical profiles $C$ for MSMB - Cancale $\left(n_{s}=15 \%\right.$, solid lines $)$ and MSMB - Hirel ( $n_{s}=30 \%$, dashed lines) experiments simulated following the Method $2\left(k=k_{e}\right)$ with a common set of parameters (see Table 3): (a) MSMB - C1/H1; (b) MSMB - C2/H2; and (c) MSMB - C3/H3. 

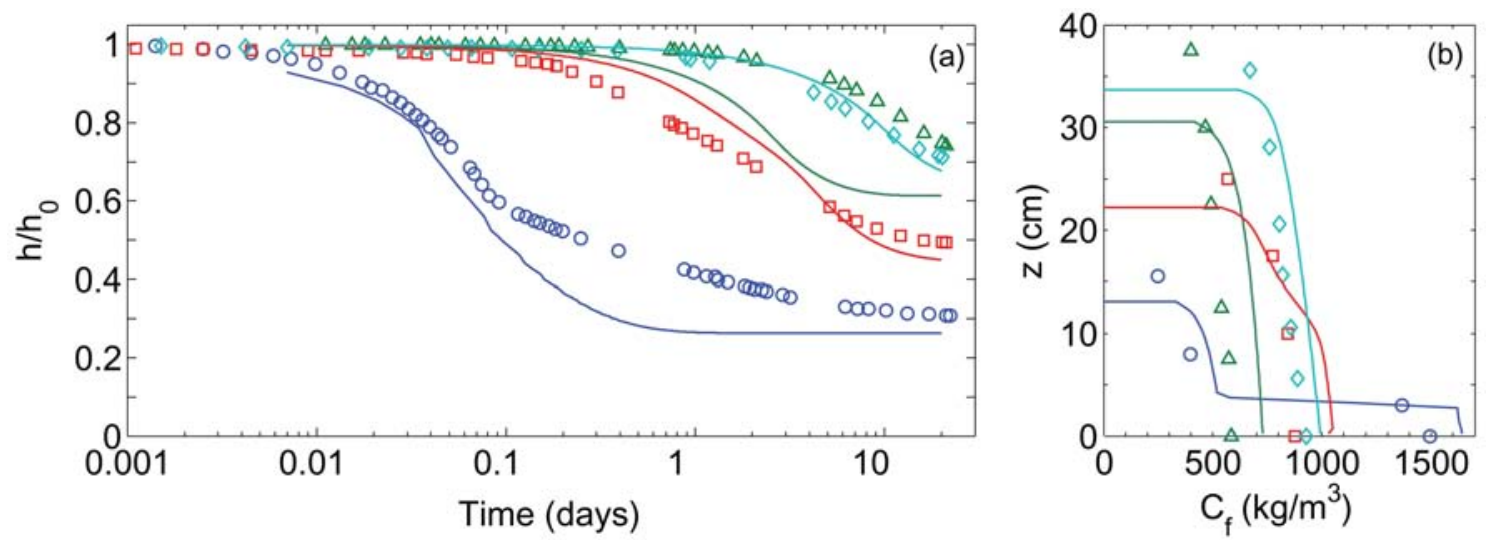

Fig. 9 (a) Time evolution of the relative sediment height $h / h_{0}$ and (b) final vertical profiles of sediment mass concentration $C_{f}$ for SE experiments (symbols) and numerical simulations (lines) following the Method 2 $\left(k=k_{e}\right)$ with a common set of parameters (see Table 3): SE - 1 (circles, blue); SE - 2 (triangles, green); SE - 3 (squares, red); SE - 5 (diamonds, cyan).
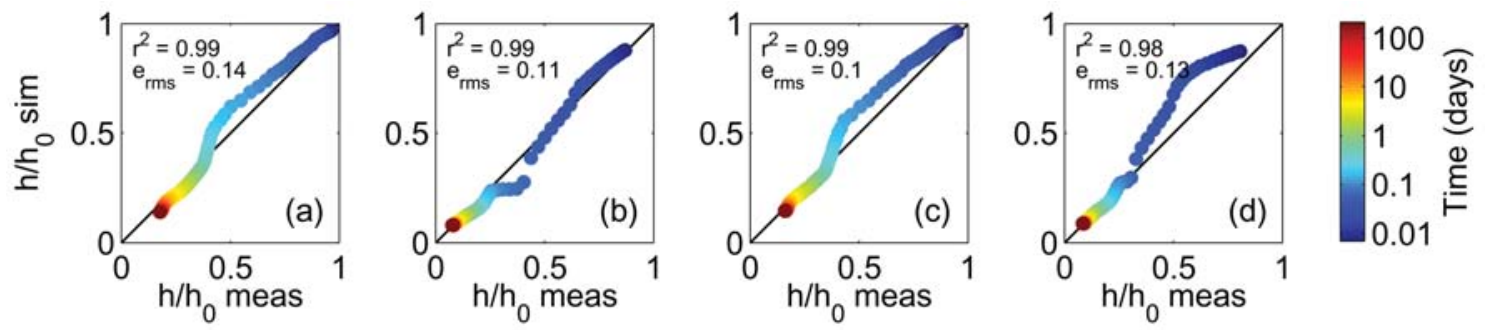

Fig. 10 Comparison between the relative sediment height $h / h_{0}$ measured and simulated following the Method 1 $\left(k=\operatorname{MIN}\left[k_{\phi}, k_{e}\right]\right)$ with a common set of parameters for initial concentrations $C<120 \mathrm{~kg} / \mathrm{m}^{3}$ (see Table 3), as a function of time: (a) MSMB - C3; (b) MSMB - C4; (c) MSMB - H3; and (d) MSMB - H4. $r^{2}$ is the squared correlation coefficient and $e_{r m s}$ is the normalized root mean square error. 
Table 1 Initial conditions of settling column experiments simulated with the model.

\begin{tabular}{ccccc}
\hline Tests & $C\left(\mathrm{~kg} / \mathrm{m}^{3}\right)$ & $n_{s}(\%)$ & $C_{\text {relmud }}\left(\mathrm{kg} / \mathrm{m}^{3}\right)$ & $h_{0}(\mathrm{~m})$ \\
\hline MSMB - C1 & 405 & 15 & 352 & 1 \\
MSMB - C2 & 201 & 15 & 173 & 1 \\
MSMB - C3 & 106 & 15 & 91 & 1 \\
MSMB - C4 & 54 & 15 & 46 & 1 \\
MSMB - H1 & 392 & 30 & 287 & 1 \\
MSMB - H2 & 219 & 30 & 157 & 1 \\
MSMB - H3 & 119 & 30 & 84 & 1 \\
MSMB - H4 & 66 & 30 & 47 & 1 \\
SE - 1 & 200 & 50 & 104 & 0.5 \\
SE - 2 & 400 & 20 & 330 & 0.5 \\
SE - 3 & 400 & 50 & 216 & 0.5 \\
SE - 5 & 600 & 50 & 338 & 0.5
\end{tabular}

Table 2 Initial experimental conditions and sand segregation occurrence after consolidation for settling experiments from the literature: Bartholomeeusen et al. (2002) (B02); Merckelbach and Kranenburg (2004b) (M\&K04b); Te Slaa et al. (2013) (TS13); Van and Pham Van Bang (2013) (V\&PVB13); Grasso et al. (2014) (G14). Tests were sorted in crescent $C_{\text {relmud }}$ values.

\begin{tabular}{lcccc}
\hline \multicolumn{1}{c}{ Tests } & $C\left(\mathrm{~kg} / \mathrm{m}^{3}\right)$ & $n_{s}(\%)$ & $C_{\text {relmud }}\left(\mathrm{kg} / \mathrm{m}^{3}\right)$ & Segregation \\
\hline SE - H (G14) & 64 & 17 & 53 & Yes \\
V\&PVB13 & 100 & 20 & 81 & Yes \\
MSMB - H3 (G14) & 119 & 30 & 84 & Yes \\
SE - 4 (G14) & 400 & 80 & 91 & Yes \\
M\&K04b & 105 & 10 & 95 & Yes \\
SE - G (G14) & 117 & 17 & 98 & Yes \\
SE - 1 (G14) & 200 & 50 & 104 & Yes \\
MSMB - H2 (G14) & 219 & 30 & 157 & Yes \\
MSMB - C2 (G14) & 201 & 15 & 173 & Yes \\
\hline O5 (TS13) & 211 & 5 & 207 & No \\
SE - 3 (G14) & 400 & 50 & 216 & No \\
Bay of Brest (G14) & 326 & 22 & 258 & No \\
Side5 (B02) & 504 & 50 & 278 & No \\
MSMB - H1 (G14) & 392 & 30 & 287 & No \\
M5 (TS13) & 343 & 2 & 308 & No \\
SE - 2 (G14) & 400 & 20 & 330 & No \\
SE - 5 (G14) & 600 & 50 & 338 & No \\
MSMB - C1 (G14) & 405 & 15 & 352 & No \\
Side6 (B02) & 781 & 50 & 458 & No \\
Side1 (B02) & 795 & 50 & 468 & No \\
Side2 (B02) & 870 & 50 & 520 & No \\
Side3 (B02) & 893 & 50 & 537 & No \\
\hline
\end{tabular}


Table 3 Constitutive relationship parameters and prediction skills between the experimental data and the model simulations. $r^{2}$ is the squared correlation coefficient and $e_{r m s}$ is the normalized root mean square error computed on 200 and 20 days for MSMB and SE, respectively. To guarantee the prediction skill consistency between the different tests, all the data and simulations were interpolated on the same time log scale.

\begin{tabular}{ccccccccc}
\hline & Tests & $K_{k}$ & $K_{\sigma}$ & $\mathrm{n}$ & $k_{1}$ & $k_{2}$ & $r^{2}$ & $e_{r m s}$ \\
\hline \multirow{2}{*}{ Individual } & MSMB - C2 & $210^{-14}$ & $1.510^{8}$ & 8.9 & $210^{-9}$ & 4.5 & 0.994 & 0.06 \\
parameters & MSMB - C3 & $610^{-13}$ & $9.310^{6}$ & 6.6 & $310^{-9}$ & 3.7 & 0.998 & 0.04 \\
& MSMB - C4 & $4.910^{-12}$ & $610^{5}$ & 5.7 & $1.510^{-9}$ & 3.7 & 0.997 & 0.06 \\
\hline & MSMB - C1 & $/$ & $510^{8}$ & 9 & $410^{-9}$ & 3.7 & 0.98 & 0.06 \\
& MSMB - C2 & $/$ & $510^{8}$ & 9 & $410^{-9}$ & 3.7 & 0.91 & 0.16 \\
& MSMB - C3 & $/$ & $510^{8}$ & 9 & $410^{-9}$ & 3.7 & 0.97 & 0.19 \\
& MSMB - C4 & $/$ & $510^{8}$ & 9 & $410^{-9}$ & 3.7 & 0.93 & 0.3 \\
Common & MSMB - H1 & $/$ & $510^{8}$ & 9 & $410^{-9}$ & 3.7 & 0.99 & 0.04 \\
parameters & MSMB - H2 & $/$ & $510^{8}$ & 9 & $410^{-9}$ & 3.7 & 0.93 & 0.14 \\
& MSMB - H3 & $/$ & $510^{8}$ & 9 & $410^{-9}$ & 3.7 & 0.97 & 0.16 \\
& MSMB - H4 & $/$ & $510^{8}$ & 9 & $410^{-9}$ & 3.7 & 0.93 & 0.26 \\
& SE - 1 & $/$ & $510^{8}$ & 9 & $410^{-9}$ & 3.7 & 0.96 & 0.24 \\
& SE - 2 & $/$ & $510^{8}$ & 9 & $410^{-9}$ & 3.7 & 0.81 & 0.14 \\
& SE - 3 & $/$ & $510^{8}$ & 9 & $410^{-9}$ & 3.7 & 0.96 & 0.06 \\
& SE - 5 & $/$ & $510^{8}$ & 9 & $410^{-9}$ & 3.7 & 0.98 & 0.02 \\
\hline \multirow{2}{*}{ Common } & MSMB - C3 & $410^{-12}$ & $610^{5}$ & 6 & $210^{-9}$ & 3.7 & 0.99 & 0.14 \\
C < 120 kg/m ${ }^{3}$ & MSMB - C4 & $410^{-12}$ & $610^{5}$ & 6 & $210^{-9}$ & 3.7 & 0.99 & 0.11 \\
& MSMB - H3 & $410^{-12}$ & $610^{5}$ & 6 & $210^{-9}$ & 3.7 & 0.99 & 0.10 \\
& MSMB - H4 & $410^{-12}$ & $610^{5}$ & 6 & $210^{-9}$ & 3.7 & 0.98 & 0.13 \\
\hline
\end{tabular}

